\title{
Pediatric Reference Intervals for Free Thyroxine and Free Triiodothyronine by Equilibrium Dialysis-Liquid Chromatography-Tandem Mass Spectrometry
}

\author{
Sonia L. La'ulu1* ${ }^{*}$ Kyle J. Rasmussen ${ }^{*}{ }^{*}$, Joely A. Straseski1,2 \\ ${ }^{1}$ ARUP Institute for Clinical and Experimental Pathology, Salt Lake City, Utah, USA \\ 2 University of Utah Health Sciences Center, Department of Pathology, Salt Lake City, Utah, USA \\ *These authors contributed equally to this work.
}

\section{WHAT IS ALREADY KNOWN ON THIS TOPIC?}

Early detection of thyroid abnormalities is critical in young children. However, the challenges of determining pediatric reference intervals (Rls) are well known. Obtaining sufficient sample numbers in healthy children is often exceedingly difficult and underscores the importance of reporting these types of studies. Free thyroxine $\left(\mathrm{fT}_{4}\right)$ and free triiodothyronine $\left(\mathrm{fT}_{3}\right)$ Rls have additional complexities, including accurate measurement of free hormones and the necessity of screening for subclinical thyroid disease in the reference population.

\section{WHAT THIS STUDY ADDS?}

This work provides nonparametric Rls for $\mathrm{fT}_{4}$ and $\mathrm{fT}_{3}$ for children from 6 months through 17 years of age. Uniquely, our study utilized a significant number of samples $(n=2213)$ from both healthy boys $(n=|| 3 \mid)$ and girls $(n=\mid 082)$. All individuals were screened for thyroid stimulating hormone and thyroid autoantibodies prior to inclusion in our study and had no known medical conditions or medication use. This study was performed using an in-house equilibrium dialysis-high performance liquid chromatography-tandem mass spectrometry method. We point out the importance of determining method-specific intervals, which has been recommended, particularly for $\mathrm{fT}_{4}$. This work will be useful for any laboratory or clinician serving a pediatric population.

\section{ABSTRACT}

Objective: Thyroid hormone concentrations fluctuate during growth and development. To accurately diagnose thyroid disease in pediatric patients, reference intervals (RIs) should be established with appropriate age groups from an adequate number of healthy subjects using the most exact methods possible. Obtaining statistically useful numbers of healthy patients is particularly challenging for pediatric populations. The objective of this study was to determine non-parametric Rls for free thyroxine $\left(\mathrm{fT}_{4}\right)$ and free triiodothyronine $\left(\mathrm{fT}_{3}\right)$ using equilibrium dialysis-high performance liquid chromatography-tandem mass spectrometry with over 2200 healthy children 6 months- 17 years of age.

Methods: Subjects were negative for both thyroglobulin and thyroid peroxidase autoantibodies and had normal thyrotropin concentrations. The study included 2213 children (1129 boys and 1084 girls), with at least 120 subjects (average of 125) from each year of life, except for the 6 month to 1 year age group ( $n=96$ ).

Results: Non-parametric Rls (95th percentile) for $\mathrm{fT}_{4}$ were: $18.0-34.7 \mathrm{pmol} / \mathrm{L}$ (boys and girls, 6 months-6 years) and 14.2-25.7 pmol/L (boys and girls, 7-17 years). Rls for $\mathrm{fT}_{3}$ were: $5.8-13.1 \mathrm{pmol} / \mathrm{L}$ (girls, 6 months- 6 years); $5.7-11.8$ $\mathrm{pmol} / \mathrm{L}$ (boys, 6 months-6 years); $5.7-10.0 \mathrm{pmol} / \mathrm{L}$ (boys and girls, 7-12 years); 4.5-8.6 pmol/L (girls, 13-17 years); and 5.2-9.4 pmol/L (boys, 13-17 years).

Conclusion: Numerous significant differences were observed between pediatric age groups and previously established adult ranges. This emphasizes the need for well-characterized Rls for thyroid hormones in the pediatric population.

Keywords: Pediatric, reference interval, free thyroxine, free triiodothyronine, mass spectrometry

Conflict of interest: None declared

Received: 11.06 .2015

Accepted: 30.09 .2015

Address for Correspondence

Joely A. Straseski PhD, ARUP Institute for Clinical and Experimental Pathology, Salt Lake City, Utah, USA Phone: (800) 242-2787 ext. 3696 E-mail: joely.a.straseski@aruplab.com OJournal of Clinical Research in Pediatric Endocrinology, Published by Galenos Publishing. 


\section{Introduction}

Identifying thyroid dysfunction is critical in young children. An imbalance in thyroid hormone concentrations early in life can have long-term ramifications, such as developmental delays, mental and/or growth retardation. Numerous conditions affecting the thyroid gland in children and adolescents may result in thyroid dysfunction. Primary congenital hypothyroidism is one of the more common thyroid abnormalities that can occur in children, with a prevalence of 1 in 3000 infants (1). It results when the thyroid gland is unable to produce sufficient amounts of thyroxine $\left(T_{4}\right)$ or triiodothyronine $\left(T_{3}\right)$. Graves' disease is the most common cause of hyperthyroidism in children, and although rare, can be fatal if not properly diagnosed and treated (2).

Symptoms of thyroid disease are not always obvious in healthy populations, therefore, laboratory measurements are of increased value. Thyroid stimulating hormone (TSH) is the initial screening test for assessment of thyroid dysfunction. The dynamic equilibrium that exists between free and proteinbound forms of $T_{3}$ and $T_{4}$ hormones makes the assessment of their in vivo concentrations complex. Free thyroxine $\left(\mathrm{fT}_{4}\right)$ and free triiodothyronine $\left(\mathrm{fT}_{3}\right)$ are analyzed when additional diagnostic information is needed in patients with suspected thyroid disease. Identifying the presence of thyroglobulin autoantibodies (TgAb) or thyroid peroxidase autoantibodies (TPOAb) is also useful in detecting autoimmune disorders that affect thyroid function (3).

Establishing reference intervals (RI) for thyroid function tests in healthy pediatric subjects is essential to effectively diagnose disease in this patient population. The National Academy of Clinical Biochemistry recommends obtaining method-specific Rls for thyroid hormones, particularly for $\mathrm{fT}_{4}$ (4). Mass spectrometry is considered a more specific method overall, particularly in challenging populations and situations requiring accurate measurement of small concentrations. Separation techniques such as equilibrium dialysis are useful for obtaining more accurate and consistent results in cases where alterations in thyroid hormone binding protein concentrations are suspected (4).

Getting access to samples from truly healthy individuals, particularly children, is often complicated. Challenges include obtaining consent, defining the healthy status in various stages of childhood development, restrictions imposed by institutional review boards, and small sample volumes due to maximum blood draw limits. These complexities often lead to small data sets that lack statistical power. The samples included in this study were from a well-characterized repository $\left(\mathrm{CHILDx}{ }^{\circledR}\right.$ program) that included sufficient information to confirm the health status of over 6000 children in total.

The purpose of this study was to improve the clinical utility of diagnostic tools available to physicians working with pediatric patients suspected of thyroid disease. Non-parametric Rls were established for $\mathrm{fT}_{4}$ and $\mathrm{fT}_{3}$ by equilibrium dialysis-high performance liquid chromatography-tandem mass spectrometry (ED-LC-MS/MS) using a well-characterized, healthy population of children ages 6 months-17 years $(n=2213)$. Importantly, the population used for these determinations had normal TSH concentrations, lacked thyroid autoantibodies, and were of sufficient sample size to apply non-parametric statistics.

\section{Methods}

\section{Sample Acquisition}

Samples used for this study were part of the CHILDx ${ }^{\circledR}$ repository of samples from healthy children. Two different approaches were used for sample acquisition. Children 6 months- 6 years of age were assessed for enrollment by a physician assistant at Primary Children's Medical Center (Salt Lake City, Utah) prior to elective, non-invasive, outpatient surgery, such as dental surgery, umbilical hernia repairs, nevus removals, orchiopexies, or orthopedic procedures. No unhealthy, medicated, or inpatient children were enrolled. Blood was drawn while patients were under gas anesthesia but prior to general anesthesia administered by IV. For children 7-17 years of age, subjects volunteered to participate and were recruited by institutional review board (IRB)-approved flyers, advertisements in magazines, and by word of mouth. An evaluation was conducted that included a full physical examination followed by blood and urine collection. Subjects were excluded for known medical conditions, medication use (other than seasonal allergy medication), or had a medical history that would consider them to be unhealthy. Eligible subjects from both age groups were enrolled after obtaining parental permission. All subject enrollment and testing protocols were approved by the University of Utah IRB.

\section{Sample Processing and Testing}

Blood was drawn into serum separator tubes and allowed to coagulate for 30 minutes prior to centrifugation. All samples were aliquoted and cryogenically frozen. In an effort to include only subjects with normal thyroid function, all samples were tested for TgAb and TPOAb on the ARCHITECT i2000SR (Abbott Diagnostics, Abbott Park, IL). Upper reference limits of $14.4 \mathrm{IU} / \mathrm{mL}$ for $\mathrm{TgAb}$ and $3.9 \mathrm{IU} / \mathrm{mL}$ for TPOAb were determined previously (5). Autoantibody negative samples were then tested for TSH (MODULAR ANALYTICS E170, Roche Diagnostics, Indianapolis, IN) to establish TSH RIs specific for our population. The central 95\% non-parametric RI was established for TSH and samples outside of these ranges were excluded from $\mathrm{fT}_{4}$ and $\mathrm{fT}_{3}$ testing. Analysis by ED-LC$\mathrm{MS} / \mathrm{MS}$ for $\mathrm{fT}_{4}$ and $\mathrm{fT}_{3}$ was performed as previously described (6). Briefly, serum samples were dialyzed 1:1 against a simple protein-free buffer for 20 hours at $37^{\circ} \mathrm{C}$. Thyroid hormones in dialysates were purified by online solid-phase extraction, then 
La'ulu SL et al.

Free Thyroxine and Free Triiodothyronine Pediatric Reference Intervals

chromatographically separated and quantified in positive ion and multiple reaction monitoring modes. Total imprecision was reported to be $<10 \%$. Adult non-parametric $\mathrm{fT}_{4}$ and $\mathrm{fT}_{3} \mathrm{Rls}$ were previously established as 16.5 (95\% confidence interval (Cl), <15.1 to 17.5) to 28.6 (26.1 to $>36.9$ ) pmol/L for $\mathrm{fT}_{4}$ and $5.6(95 \% \mathrm{Cl},<4.8$ to 6.4$)$ to $10.4(95 \% \mathrm{Cl}, 10.2$ to $>10.9)$ pmol/L for $\mathrm{fT}_{3}$ ( $\mathrm{n}=67$ females, $\mathrm{n}=70$ males) (6).

\section{Statistical Analysis}

Non-parametric Rls were determined using EP Evaluator software (Data Innovations, South Burlington, VT). Differences between ages or gender were first identified by determining whether the determined reference limits were contained within the $95 \% \mathrm{Cls}$ of the adjacent group or other gender. If limits were contained within the adjacent $\mathrm{Cl}$, age groups and genders were combined. Statistical significance of the resulting partitions was confirmed by calculating p-values using GraphPad Prism (GraphPad Software, San Diego, CA). Pediatric reference limits were compared to adult $\mathrm{Cls}$ to determine whether ranges were different. Dixon's test was used to identify and remove outliers.

\section{Results}

A total of 2,540 subjects were initially evaluated for this study. Subjects with thyroid autoantibody concentrations above the established thresholds $(n=172)$ and TSH concentrations outside the determined Rls $(n=155)$ were excluded from Rl analysis for $\mathrm{fT}_{4}$ and $\mathrm{fT}_{3}$. The central 95\% non-parametric Rls for $\mathrm{TSH}$, as determined using the E170 $(n=2284)$, are provided (Table 1). Subjects that were negative for thyroid autoantibodies, within the central $95 \%$ of the established $\mathrm{RI}$ for $\mathrm{TSH}$, and had sufficient volume $(\mathrm{n}=2213)$ were analyzed for $\mathrm{fT}_{4}$ and $\mathrm{fT}_{3}$ using ED-LC-MS/MS. More than 120 samples (average $n=125$ ) were tested for $\mathrm{fT}_{4}$ and $\mathrm{fT}_{3}$ from each year of life, with the exception of the 6 months- 1 year age group $(n=96)$.

The established pediatric Rls for $\mathrm{fT}_{4}$ are summarized in Table 2 along with a dot plot of the data (Figure 1). $\mathrm{FT}_{4}$ concentrations ranged from 7.7 to $87.7 \mathrm{pmol} / \mathrm{L}$ (median=20.6 pmol/L). No significant differences were observed when partitioning by
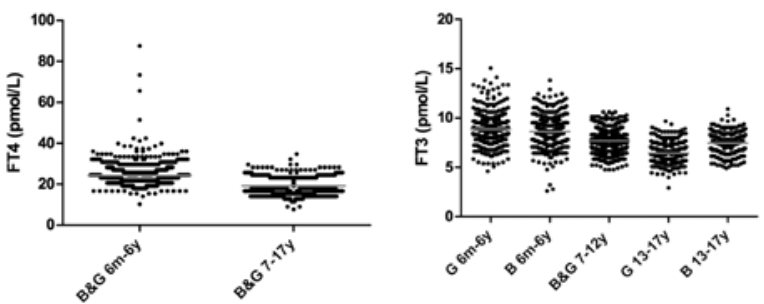

Figure 1. Scatter dot plot representation of the distribution of free thyroxine and free triiodothyronine in children ages 6 months to 17 years. Age groups and genders were combined when no significant differences were observed. The gray line represents the mean. $\mathrm{FT}_{4}$ : free thyroxine, $\mathrm{fT}_{3}$ : free triiodothyronine, $\mathrm{B}$ : boys, $\mathrm{G}$ : girls, $\mathrm{m}$ : months, $\mathrm{y}$ : years gender for $\mathrm{fT}_{4}$, therefore, genders were combined. Only differences between the 6 months- 6 years and the 7-17 years of age groups were statistically significant and warranted partitioning ( $p$-value $<0.0001$ ). Pediatric ranges were compared with RI previously established for adults (see Methods and reference 6) and were considered different if limits did not fall within the $95 \% \mathrm{Cls}$ of the adult reference limits. For $\mathrm{fT}_{4}$, there were differences between adult values and both age groups for the lower and upper limits. The lower limit for the 6 months- 6 years of age group was higher than that for adults (designated " $\mathrm{H}$ " in Table 2), while that value for the 7-17 year old age group was lower (designated " $\mathrm{L}$ " in Table 2). The $\mathrm{fT}_{4}$ upper limit was different only in the 7-17 year olds and found to be lower than that in adults.

The established pediatric RIs for $\mathrm{fT}_{3}$ are provided (Table 2, Figure 1). $\mathrm{FT}_{3}$ concentrations ranged from 2.6 to $15.1 \mathrm{pmol} / \mathrm{L}$ (median=7.9 pmol/L). Due to significant differences, genders were partitioned for the 6 months- 6 years ( $p$-value, 0.038) and 13-17 years age groups ( $p$-value $<0.0001$ ). Statistically significant differences were also observed between age groups 6 months-6 years, 7-12 years, and 13-17 years (p-values $<0.0001$ to 0.002 ). Within the 6 months- 6 years age group, upper limits were higher in girls than boys. In contrast, upper limits were higher for boys than girls in the oldest age group (13-17 year olds). Upper limits were higher for ages 6 months-6 years than for all other age groups. When compared to adult $\mathrm{RI}$, the only difference observed for the $\mathrm{fT}_{3}$ lower limit was for 13-17 year old girls being lower than that for adults. However, for the $\mathrm{fT}_{3}$ upper limit, all of the pediatric age groups were different than the adult population; 6 months- 6 year olds (both boys and girls) were higher and both of the older age groups were lower than the adult range.

\section{Discussion}

Thyroid dysfunction during childhood development may result in serious outcomes, including mental impairment and growth delays. Early diagnosis allows for rapid intervention that can almost entirely reverse symptoms. This study was performed to improve clinicians' ability to correctly diagnose thyroid disorders in children by providing population-specific Rls. Providing accurate Rls requires testing of well-characterized, healthy patients from a sample set of adequate size to provide statistical relevance. These criteria are particularly difficult to meet in pediatric populations; however, we were able to address both in this study.

TSH results are often used as the primary indicator for assessing thyroid dysfunction and may be followed by $\mathrm{fT}_{4}$ and $\mathrm{fT}_{3}$ testing when $\mathrm{TSH}$ results are close to reference limits or if further evidence of thyroid disease is required. Even though our main focus was to establish Rls for $\mathrm{fT}_{4}$ and $\mathrm{fT}_{3}$, those results could be skewed by including children with unapparent thyroid disorders. Because symptoms of thyroid disease are not always recognized or diagnosed, we screened samples and 
La'ulu SL et al.

Free Thyroxine and Free Triiodothyronine Pediatric Reference Intervals

\begin{tabular}{|c|c|c|c|c|c|c|}
\hline Gender & Age range & $\mathbf{n}$ & Lower limit (mIU/L) & 95\% Cl (lower limit) & Upper limit (mIU/L) & 95\% Cl (upper limit) \\
\hline G & $6 \mathrm{~m}-2 \mathrm{y}$ & 159 & 0.85 & $0.69-1.10$ & 5.78 & $5.48-6.68$ \\
\hline B & $6 \mathrm{~m}-2 \mathrm{y}$ & 188 & 1.07 & $0.87-1.30$ & 7.57 & $6.08-9.29$ \\
\hline G & $3-4 y$ & 122 & 0.80 & $0.56-1.00$ & 6.90 & $5.25-7.56$ \\
\hline B & $3-4 y$ & 125 & 1.10 & $0.99-1.34$ & 6.56 & $5.32-7.68$ \\
\hline G & $5-6 y$ & 121 & 0.85 & $0.69-1.08$ & 5.83 & $5.11-7.83$ \\
\hline B & $5-6 y$ & 126 & 1.00 & 0.87-1.12 & 6.51 & $5.58-8.35$ \\
\hline$B \& G$ & $7 y$ & 137 & 1.12 & $0.97-1.32$ & 5.66 & $4.82-6.04$ \\
\hline G & $8-9 y$ & 131 & 0.94 & $0.87-1.15$ & 5.40 & $4.53-5.89$ \\
\hline$B$ & $8-9 y$ & 133 & 1.14 & $0.97-1.25$ & 6.41 & $4.75-7.34$ \\
\hline G & $10-11$ y & 135 & 0.94 & $0.80-1.04$ & 4.71 & $3.78-6.12$ \\
\hline B & $10-11$ y & 131 & 0.78 & $0.65-0.94$ & 6.11 & $4.20-6.76$ \\
\hline G & $12-13 y$ & 129 & 0.88 & $0.51-0.89$ & 4.71 & 4.23-5.71 \\
\hline B & $12-13 y$ & 130 & 0.77 & $0.71-0.94$ & 4.32 & $4.14-4.90$ \\
\hline G & $14-15 y$ & 130 & 0.47 & $0.31-0.74$ & 4.56 & $3.63-6.46$ \\
\hline B & $14-15 y$ & 127 & 0.65 & $0.59-0.92$ & 4.16 & $3.49-4.63$ \\
\hline G & $16-17 y$ & 127 & 0.56 & $0.10-0.68$ & 4.62 & $3.19-5.11$ \\
\hline B & $16-17 y$ & 133 & 0.63 & $0.37-0.84$ & 4.58 & $3.67-5.28$ \\
\hline
\end{tabular}

Table 2. Pediatric reference intervals for free thyroxine and free triiodothyronine using equilibrium dialysis-high performance liquid chromatographytandem mass spectrometry

\begin{tabular}{|c|c|c|c|c|c|c|c|}
\hline Analyte & Gender & Age range & $\mathrm{n}$ & $\begin{array}{l}\text { Lower limit } \\
\text { (pmol/L) }\end{array}$ & $\begin{array}{l}95 \% \text { CI } \\
\text { (lower limit) }\end{array}$ & $\begin{array}{l}\text { Upper limit } \\
\text { (pmol/L) }\end{array}$ & $\begin{array}{l}95 \% \mathrm{CI} \\
\text { (upper limit) }\end{array}$ \\
\hline $\mathrm{fT}_{4}$ & $B \& G$ & $6 \mathrm{~m}-6 \mathrm{y}$ & 840 & $18.0 \mathrm{H}$ & $16.7-18.0$ & 34.7 & $33.0-37.3$ \\
\hline $\mathrm{fT}_{4}$ & $B \& G$ & $7-17 y$ & 1373 & $14.2^{\mathrm{L}}$ & $14.2-14.2$ & $25.7^{\mathrm{L}}$ & $25.7-27.0$ \\
\hline $\mathrm{fT}_{3}$ & $G$ & $6 \mathrm{~m}-6 \mathrm{y}$ & 401 & 5.8 & 5.4-6.3 & $13.1^{\mathrm{H}}$ & $12.1-13.4$ \\
\hline $\mathrm{fT}_{3}$ & $B$ & $6 \mathrm{~m}-6 \mathrm{y}$ & 438 & 5.7 & $5.4-6.3$ & $11.8^{\mathrm{H}}$ & $11.5-12.1$ \\
\hline $\mathrm{fT}_{3}$ & $B \& G$ & $7-12 y$ & 759 & 5.7 & $5.4-5.8$ & $10.0^{\mathrm{L}}$ & $9.8-10.1$ \\
\hline $\mathrm{fT}_{3}$ & G & $13-17 y$ & 305 & $4.5^{\mathrm{L}}$ & $4.3-4.8$ & $8.6 \mathrm{~L}$ & $8.6-9.1$ \\
\hline $\mathrm{fT}_{3}$ & $B$ & $13-17 y$ & 310 & 5.2 & $5.1-5.5$ & $9.4^{\mathrm{L}}$ & $9.1-9.8$ \\
\hline
\end{tabular}

only included those that were thyroid autoantibody negative and were within the determined TSH RI.

Thyroid hormone concentrations are highest immediately following birth (7). TSH concentrations rise in response to the temperature shock of leaving the in utero environment, which in turn increases the concentrations of $T_{4}$ and $T_{3}$. Higher TSH concentrations are also expected in children due to progressive maturation and modulation of the hypothalamic-pituitary-thyroid axis during development (8). Expectedly, the TSH RIs that were established for children in this study were higher than the recommended range for adults (0.3-3.0 $\mathrm{mlU} / \mathrm{L})(4)$ and gradually decreased with age.
Initial partitioning of gender and age groups showed no significant differences for $\mathrm{fT}_{4}$; therefore, genders and most age groups were combined. In contrast, the $\mathrm{fT}_{3} \mathrm{Rls}$ showed significant differences between age and gender and more partitions were required. Differences were particularly notable in girls where the difference between upper limits of girls' ages 6 months- 6 years and girls' ages 13-17 years was 34\%. There are conflicting data regarding gender differences for $\mathrm{fT}_{3}$ in pediatric populations. Similar to our findings, the decline of $\mathrm{fT}_{3}$ in girls during puberty has been observed previously, whereas concentrations in boys remained seemingly constant $(9,10,11)$. Kapelari et al (12) also established gender-specific 
Rls for $\mathrm{fT}_{3}$ and did not report significant gender differences for $\mathrm{fT}_{4}$ using the ADVIA Centaur. However, Hübner et al (13) observed gender differences for $\mathrm{fT}_{3}$ only within the 11-14 age group, which is in contrast to ours and other studies where no statistically significant differences were observed between genders for the 13-17 year age group. Moreover, differences between boys and girls for the upper limit of $\mathrm{fT}_{3}$ were not reported previously by Soldin et al (14) using similar methodology to our study. The differences described here may be attributed to known differences in thyroid hormone concentrations among populations and/or methods $(15,16)$. Of note, we have previously observed ethnic differences in thyroid hormones in pregnant individuals $(17,18)$, and ethnicity has not been addressed in these pediatric populations. Furthermore, either lower limits, upper limits, or both, from children for $\mathrm{fT}_{4}$ and $\mathrm{fT}_{3}$ were significantly different from adult RIs (6), for every age group. The above comparisons and the numerous significant differences observed further emphasize the necessity of establishing reference ranges specific to pediatric populations.

Soldin et al (14) performed testing on pediatric subjects by LC-MS/MS using an ultrafiltration method rather than equilibrium dialysis for isolation of free hormones. For $\mathrm{fT}_{4}$, our RIs using ED were comparable to those determined by Soldin et al (14) using ultrafiltration performed at $37^{\circ} \mathrm{C}$. Our lower reference limits for $\mathrm{fT}_{3}$ were higher than the limits determined by ultrafiltration performed at both $37^{\circ} \mathrm{C}$ and $25^{\circ} \mathrm{C}$. The upper reference limits showed some similarities for $\mathrm{fT}_{3}$ with the exception of our younger age groups being higher.

In comparison to a candidate international reference method, our ED-LC-MS/MS method demonstrated a positive bias for both $\mathrm{fT}_{4}$ and $\mathrm{fT}_{3}$ (19). Until standardization efforts of free thyroid hormone assays/methods are established, caution should be used when interpreting Rls. Laboratories need to verify Rls specific to the method and population they are using and evaluating, particularly for thyroid function testing.

A limitation of these RIs is that all samples were taken from patients living in the region surrounding Salt Lake City, UT. This resulted in a less diverse population (96\% Caucasian). Due to IRB limitations, children under 6 months of age were excluded. Although thyroid testing is part of most newborn screening programs, additional studies would be needed to determine Rls for these analytes using this ED-LC-MS/MS method in preterm and newborn populations.

Detecting thyroid dysfunction early in development is critical to reversing long-term symptoms. This study provides useful Rls established from over 2200 healthy children using equilibrium dialysis and mass spectrometry, the preferred methods of analysis for $\mathrm{fT}_{4}$ and $\mathrm{fT}_{3}$ hormones. Having Rls for this specific patient population improves the ability of physicians to properly diagnose and treat children suspected of these often reversible thyroid abnormalities.

\section{Acknowledgements}

The authors wish to acknowledge the late William $L$. Roberts, MD, PhD for the generation of the healthy child repository and the contributions to development of the ED-LCMS/MS assay. The authors also gratefully acknowledge John Simmons, P.A. and Ashley Bunker for patient enrollment and specimen collection as well as Primary Children's Medical Center for allowing us to enroll children at their facility. Support for this study was provided by the ARUP Institute for Clinical and Experimental Pathology.

\section{Ethics}

Ethics Committee Approval: University of Utah Institutional Review Board; (protocols: 9200\&15079), Informed Consent: Yes, by subject or guardian.

Peer-review: External peer-reviewed.

\section{Authorship Contributions}

Concept: William Roberts (late), Design: William Roberts (late), Sonia L. La'ulu, Data Collection or Processing: Sonia L. La'ulu, Kyle J. Rasmussen, Analysis or Interpretation: Sonia L. La'ulu, Kyle J. Rasmussen, Joely A. Straseski, William Roberts (late), Literature Search: Sonia L. La'ulu, Kyle J. Rasmussen, Joely A. Straseski, Writing: Sonia L. La'ulu, Kyle J. Rasmussen, Joely A. Straseski.

Financial Disclosure: ARUP Institute for Clinical and Experimental Pathology.

\section{References}

1. Wilcken B, Wiley V. Newborn screening. Pathology 2008;40:104-115.

2. Leger J, Carel JC. Hyperthyroidism in childhood: causes, when and how to treat. $\mathrm{J}$ Clin Res Pediatr Endocrinol 2013;5(Suppl 1):50-56.

3. Spencer CA, Hollowell JG, Kazarosyan M, Braverman LE. National health and nutrition examination survey III thyroid-stimulating hormone (TSH)-thyroperoxidase antibody relationships demonstrate that TSH upper reference limits may be skewed by occult thyroid dysfunction. J Clin Endocrinol Metab 2007;92:4236-4240. Epub 2007 Aug 7

4. Baloch Z, Carayon P, Conte-Devolx B, Demers LM, FeldtRasmussen U, Henry JF, LiVosli VA, Niccoli-Sire P, John R, Ruf J, Smyth PP, Spencer CA, Stockigt JR; Guidelines Committee, National Academy of Clinical Biochemistry. Laboratory medicine practice guidelines. Laboratory support for the diagnosis and monitoring of thyroid disease. Thyroid 2003;13:3-126.

5. La'ulu SL, Slev PR, Roberts WL. Performance characteristics of 5 automated thyroglobulin autoantibody and thyroid peroxidase autoantibody assays. Clin Chim Acta 2007;376:8895. Epub 2006 Jul 25

6. Yue B, Rockwood AL, Sandrock T, La'ulu SL, Kushnir MM, Meikle AW. Free thyroid hormones in serum by direct equilibrium dialysis and online solid-phase extraction-liquid chromatography/tandem mass spectrometry. Clin Chem 2008;54:642-651. Epub 2008 Feb 7 
La'ulu SL et al.

Free Thyroxine and Free Triiodothyronine Pediatric Reference Intervals

7. Fisher DA, Klein AH. Thyroid development and disorders of thyroid function in the newborn. N Engl J Med 1981;304:702712.

8. Penny R, Spencer CA, Frasier SD, Nicoloff JT. Thyroidstimulating hormone and thyroglobulin levels decrease with chronological age in children and adolescents. J Clin Endocrinol Metab 1983;56:177-180.

9. Dunger DB, Perkins JA, Jowett TP, Edwards PR, Cox LA, Preece MA, Ekins RP. A longitudinal study of total and free thyroid hormones and thyroxine binding globulin during normal puberty. Acta Endocrinol (Copenh) 1990;123:305310.

10. Fleury $Y$, Van Melle G, Woringer V, Gaillard RC, Portmann L. Sex-dependent variations and timing of thyroid growth during puberty. J Clin Endocrinol Metab 2001;86:750-754.

11. Parra A, Villalpando $S$, Junco $E$, Urquieta $B$, Alatorre $S$, Garcia-Bulnes G. Thyroid gland function during childhood and adolescence. Changes in serum TSH, T4, T3, thyroxinebinding globulin, reverse $\mathrm{T} 3$ and free $\mathrm{T} 4$ and $\mathrm{T} 3 \mathrm{concentrations.}$ Acta Endocrinol (Copenh) 1980;93:306-341.

12. Kapelari K, Kirchlechner C, Högler W, Schweitzer K, Virgolini I, Moncayo R. Pediatric reference intervals for thyroid hormone levels from birth to adulthood: A retrospective study. BMC Endocr Disord 2008;8:15.

13. Hübner $U$, Englisch $C$, Werkmann $H$, Butz $H$, Georgs T, Zabransky S, Herrmann W. Continuous age-dependent reference ranges for thyroid hormones in neonates, infants, children and adolescents established using the ADVIA Centaur analyzer. Clin Chem Lab Med 2002;40:1040-1047.

14. Soldin OP, Jang M, Guo T, Soldin SJ. Pediatric reference intervals for free thyroxine and free triiodothyronine. Thyroid 2009;19:699-702.

15. Demers LM, Spencer CA. Laboratory medicine practice guidelines: laboratory support for the diagnosis and monitoring of thyroid disease. Clin Endocrinol (Oxf) 2003;58:138-140.

16. d'Herbomez M, Forzy G, Gasser F, Massart C, Beaudonnet A, Sapin R. Clinical evaluation of nine free thyroxine assays: Persistent problems in particular populations. Clin Chem Lab Med 2003;41:942-947.

17. La'ulu SL, Roberts WL. Second-trimester reference intervals for thyroid tests: The role of ethnicity. Clin Chem 2007;53:1658-1664.

18. La'ulu SL, Roberts WL. Ethnic differences in first-trimester thyroid reference intervals. Clin Chem 2011;57:913-915. Epub 2011 Feb 22

19. Thienpont LM, Van Uytfanghe K, Beastall G, Faix JD, leiri T, Miller WG, Nelson JC, Ronin C, Ross HA, Thijssen JH, Toussaint B; IFCC Working Group on Standardization of Thyroid Function Tests. Report of the IFCC Working Group for Standardization of Thyroid Function Tests; part 2: free thyroxine and free triiodothyronine. Clin Chem 2010;56:912920. Epub 2010 Apr 15 